\title{
Fluoroscopy-guided endoscopic recanalization of an obstructed gastroesophageal junction in a child
}

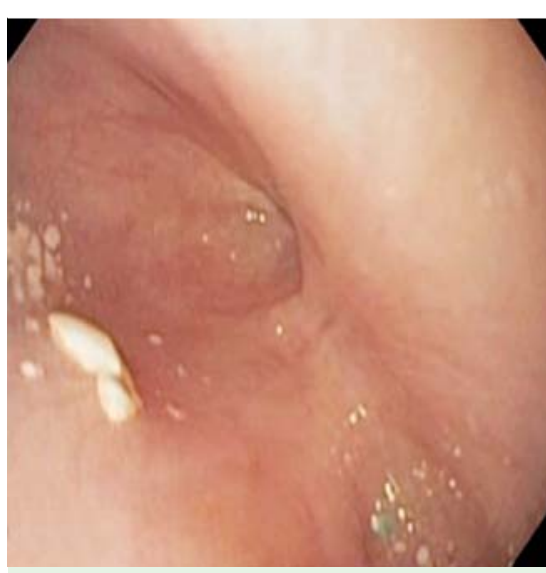

Fig. 1 Endoscopic view showing total occlusion of the distal esophagus.

There are various conditions that can lead to complete obstruction of the esophagus, with possible causes including radiotherapy, ingestion of caustic agents, foreign bodies, peptic esophagitis, and iatrogenic factors. In most situations, major surgical intervention is required to restore the patency of the alimentary tract. Standard endoscopic dilation is not possible because no lumen exists [1,2]. The presence of a gastrostomy tube may allow for a combined endoscopic and fluoroscopic approach as demonstrated by the following technique.

An 11-year-old girl had undergone an open fundoplication at another hospital for "gastroesophageal reflux" and persisting vomiting at the age of 3 days. The surgery did not resolve her problems but in fact worsened them, resulting in esophageal obstruction. In an attempt to remedy the initial surgical problem, she underwent several surgical interventions over the next few years, including gastrectomy with Billroth I reconstruction twice, gastrostomy, jejunostomy, and others. During one of these procedures, the anastomosis dehisced and she developed a gastrocutaneous fistula.

The child had never been able to take an oral diet and was unable to swallow her saliva, which caused her suffering at school because other children refused to be close to her. She was referred to our hospital, where two operations were necessary to restore gastrointestinal patency; however, the esophagus remained occluded.

We performed esophagogastroduodenoscopy (EGD) using a gastroscope (Olympus 180; Olympus, Tokyo, Japan) and found total occlusion of the distal esophagus ( Fig. 1; Video 1). The gastrostomy site was used to inject air into the stomach, making the stomach bubble clearly visible on fluoroscopy, and the esophagus was filled with water-soluble contrast ( $\bullet$ Fig.2a). We then measured the distance of the fibrotic separation between the esophagus and the stomach, which was about $10 \mathrm{~mm}$.
A 19G endoscopic ultrasound-guided fine needle aspiration (EUS-FNA) (Boston Scientific, Massachusetts, USA) was used to puncture across the fibrosis into the stomach $($ Fig. 2 b). The position of the needle in the stomach was documented by injection of contrast. After this a 0.035-inch guidewire (Jagwire; Boston Scientific) was inserted through the needle into the gastric lumen. The path was dilated initially with a Soehendra dilator (7 - 8.5 Fr; Cook Medical, Winston-Salem, North Carolina, USA) and afterwards with a 10-mm Titan biliary balloon (Cook Medical) ( $\bullet$ Fig. 2c), resulting in complete recanalization of the esophagus ( Fig.3a). Following this it was possible to easily pass the endoscope into the stomach and scheduled dilations were performed every 3-4 weeks over a period of 12 months ( Fig. $\mathbf{3} \mathbf{b}$ ).

After the recanalization of her esophagus, for the first time in her life, the child was able to ingest food without vomiting it, and her general condition, social life, and quality of life have markedly improved since then.

\section{Video 1}

Fluoroscopy-guided endoscopic recanalization and endoscopic treatment of a total occlusion of the distal esophagus, showing the final result.

Endoscopy_UCTN_Code_TTT_1AO_2AH

\section{Competing interests: None}
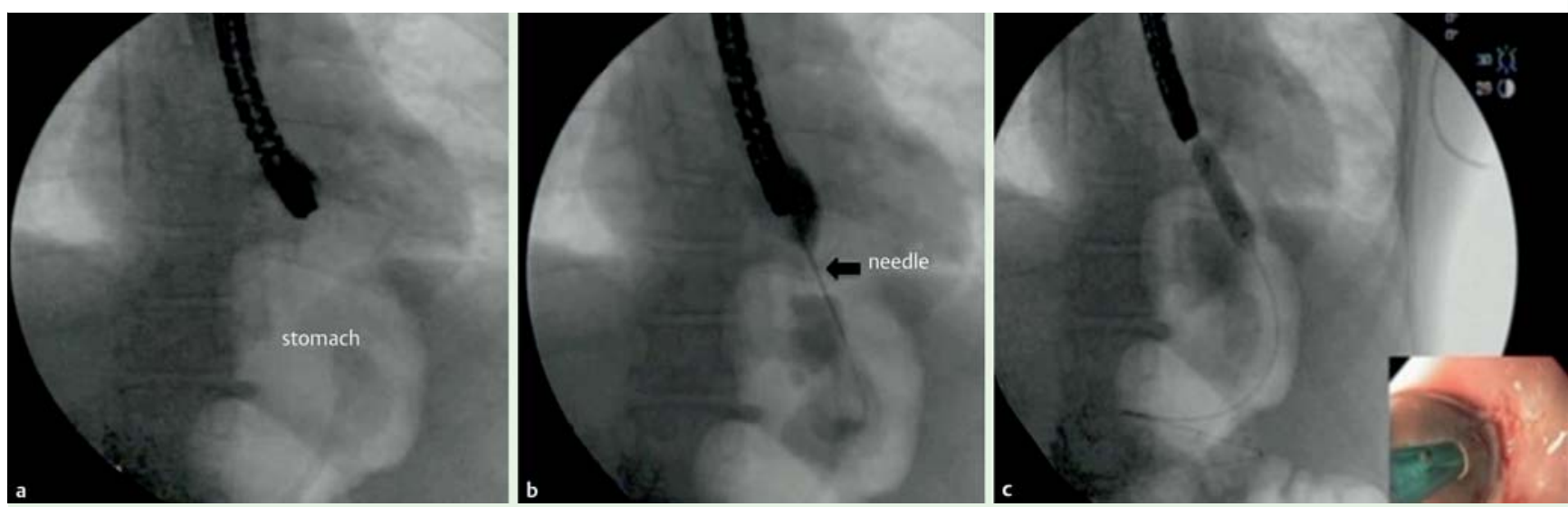

Fig. 2 Radiographic images showing: a the stomach, which has been been filled with air via the gastrostomy tube, and the esophagus, which has been filled with water-soluble contrast; $\mathbf{b}$ a fine needle aspiration (FNA) needle that has been inserted into the stomach; $\mathbf{c}$ balloon dilation of the stenosis. 


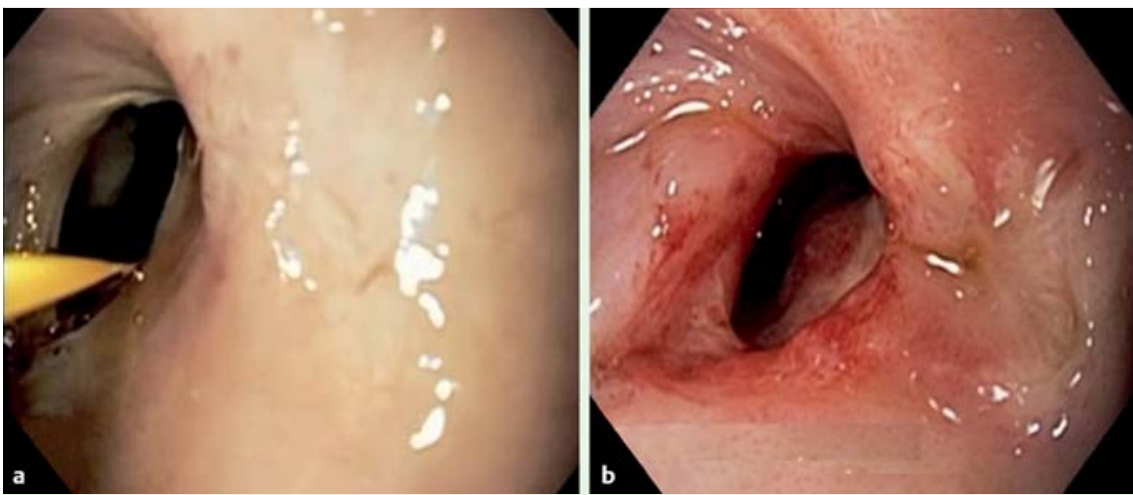

Fig. 3 Endoscopic views showing: a the esophagus immediately after successful dilation of the stenosis; $\mathbf{b}$ the appearance 21 days after recanalization.

\section{Saverio T. N. Armellini ${ }^{1}$, Daniel} Moribe ${ }^{1}$, Joao Seda², Paulo Chap Chap ${ }^{2}$, Rubens Sallun², Marco A. D’Assuncao ${ }^{1}$

${ }^{1}$ Department of Digestive Endoscopy, Hospital Sirio Libanes, Sao Paulo, Brazil

2 Department of Surgery of Hospital Sirio Libanes, Sao Paulo, Brazil

\section{References}

1 Schembre D, Dever JB, Glenn M et al. Esophageal reconstitution by simultaneous antegrade/retrograde endoscopy: re-establishing patency of the completely obstructed esophagus. Endoscopy 2011; 43: 434-437

2 Garcia A, Flores RM, Schattner M et al. Endoscopic retrograde dilation of completely occlusive esophageal strictures. Ann Thorac Surg 2006; 82: 1240-1243
Bibliography

Dol http://dx.doi.org/

10.1055/s-0034-1377285

Endoscopy 2015; 47: E195-E196

(c) Georg Thieme Verlag KG

Stuttgart · New York

ISSN 0013-726X

Corresponding author

Marco Aurelio D'Assuncao, MD

Hospital Sirio Libanes

Digestive Endoscopy Unit

Rua Adma Jafet, 91 10

SS

Sao Paulo, SP

01308-050

Brazil

Fax: +55-11-31553721

mada.endoscopia@hotmail.com 